\title{
A CADAVERIC STUDY OF MORPHOLOGY OF HUMAN SPLEEN
}

\author{
Anita Fating 1 \\ ${ }^{1}$ Associate Professor, Department of Anatomy, DVVPF'S Medical College, Ahmednagar.
}

\section{ABSTRACT}

\section{BACKGROUND}

Elaborating morphology of spleen which includes its shape, fissures, notches and comparing it with the available literature of previous studies would be beneficial for academicians and clinicians.

\section{MATERIALS AND METHODS}

The ends, borders and surfaces of the spleen were ascertained. The impressions on the visceral surface of the spleens were noted. The careful observation of notches on the borders and fissures on the surfaces were done. Thus obtained data were tabulated, analysed statistically and compared with data of the previous studies. For statistical analysis, sexual dimorphism was excluded.

\section{RESULTS}

Out of 54 spleens observed for the present study, 38.88\% wedge, $22.22 \%$ triangular, $11.11 \%$ tetrahedral, $20.37 \%$ oval \& $7.40 \%$ irregular shaped spleens were noted. $50 \%$ spleens showed notches only on superior border, $7.40 \%$ spleens showed notches only on inferior border, $22.22 \%$ spleens showed notches on both borders \& $20.37 \%$ spleens were devoid of notch. $22.22 \%$ spleens showed 1 notch, $27.77 \%$ spleens showed 2 notches, $16.66 \%$ spleens showed 3 notches, $9.25 \%$ spleens showed 4 notches, $1.85 \%$ spleens showed 5 notches \& $1.85 \%$ spleens showed 7 notches. Number of notches on superior border varied from 1 to 5 \& that on inferior border from 1 to 2 , so number of notches varies from 1 to 7 . About fissures on the surfaces, 5.55\% spleens showed fissure only on diaphragmatic surfaces, 5.55\% spleens showed fissure only on visceral surfaces, $3.70 \%$ spleens showed fissures on both surfaces \& $85.18 \%$ spleens showed no fissures.

\section{CONCLUSION}

Not only the fundamental knowledge of spleen is enhanced by such studies, but it is also of immense help in clinical utility.

\section{KEYWORDS}

Spleen, Notches, Fissures, Shapes.

HOW TO CITE THIS ARTICLE: Fating A. A cadaveric study of morphology of human spleen. J. Evolution Med. Dent. Sci. 2017;6(63): 4580-4583, DOI: $10.14260 /$ Jemds/2017/991

\section{BACKGROUND}

Spleen, a large encapsulated mass of vascular and lymphoid tissue, assumes clinical importance due to its haematological, immunological and cytological role. It is situated in the left hypochondriac quadrant between fundus of stomach and diaphragm. Its shape varies from a slightly curved wedge to a domed tetrahedron. ${ }^{1}$

Lobulated form of foetal spleen revealed as notches on the superior border near to anterior end of spleen. ${ }^{1}$ Rarely persistence of lobulated form of spleen may be in the form of deep anomalous notches on the borders or as fissures on its surfaces. ${ }^{2}$ The presence of anomalous notches or fissures may be misinterpreted as splenic injury during radiological examinations. ${ }^{3}$

The role of spleen as a blood filter was found to be very significant by a series of animal experiments and patients' followup studies which revealed actual importance of spleen in protection from blood borne sepsis. ${ }^{4}$

Financial or Other, Competing Interest: None.

Submission 03-07-2017, Peer Review 28-07-2017,

Acceptance 02-08-2017, Published 07-08-2017.

Corresponding Author:

Dr. Anita Fating,

Associate Professor,

Department of Anatomy,

Staff Quarters, D-10,

DVVPF'S Medical College,

Vilad Ghat, MIDC, Ahmednagar-414111.

E-mail: aanujdeshmukh@rediffmail.com

DOI: $10.14260 /$ jemds $/ 2017 / 991$

(c) (i) $\odot$
Although there are many instances where removal of the spleen is advocated like traumatic rupture, splenic cyst, neoplasia and hypersplenism, the present tendency of surgeons is for conservative management. So morphology of the spleen is of utmost importance for anatomists, clinicians, surgeons and radiologists. ${ }^{5}$

\section{MATERIALS AND METHODS}

The present descriptive study was conducted in the Department of Anatomy at DVVPF'S Medical College and Hospital, Ahmednagar. Intact 54 dissected \& preserved specimens of spleen of adult human cadavers of both gender [male \& female] have been selected for the study. Distorted [cut/damaged] specimens of spleens were excluded.

The ends, borders \& surfaces of spleens were ascertained. The shapes of the spleens were observed. The impressions on the visceral surface of the spleens were noted. The careful observation of notches on the borders and fissures on the surfaces were done. Thus, obtained data were tabulated \& analysed statistically. For statistical analysis, sexual dimorphism was excluded, as already dissected specimens of spleen being considered for the study.

\section{RESULTS}

Out of 54 spleens observed for the present study, 21 (38.88\%) wedge, 12 (22.22\%) triangular, 6 (11.11\%) tetrahedral, $11(20.37 \%)$ oval \& $4(7.40 \%)$ irregular shaped spleens were noted [Fig. 1]. 27 (50\%) spleens showed notches only on superior border, $4(7.40 \%)$ spleens showed notches only on inferior border, $12(22.22 \%)$ spleens showed 
notches on both borders \& $11(20.37 \%)$ spleens were devoid of notch [Fig. 2]. 12 spleens (22.22\%) showed 1 notch, 15 spleens $(27.77 \%)$ showed 2 notches, 9 spleens (16.66\%) showed 3 notches, 5 spleens $(9.25 \%)$ showed 4 notches, 1 spleen $(1.85 \%)$ showed 5 notches \& 1 spleen $(1.85 \%)$ showed 7 notches [Fig. 3]. Number of notches on superior border varied from 1 to $5 \&$ that on inferior border from 1 to 2 , so number of notches varies from 1 to 7 . About fissures on the surfaces, $3(5.55 \%)$ spleens showed fissure only on diaphragmatic surfaces, 3 (5.55\%) spleens showed fissure only on visceral surfaces, $2(3.70 \%)$ spleen showed fissures on both surfaces \& 46 (85.18\%) spleens showed no fissures [Fig. 4]. Various shapes, notches and fissures of spleens were shown in Fig. 5, 6 and 7 respectively.

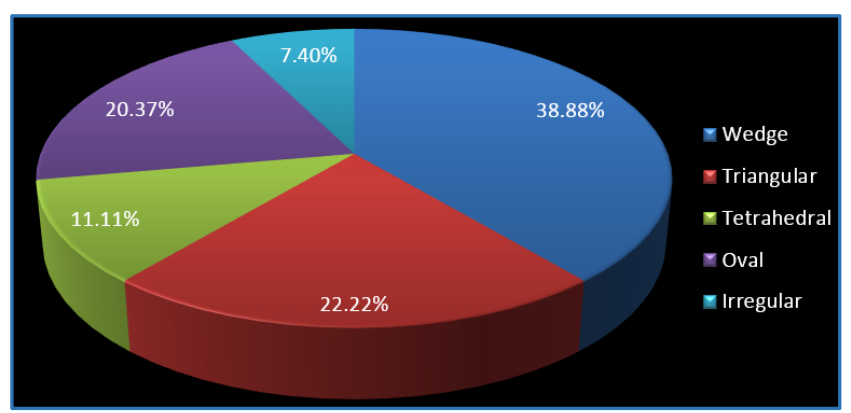

Figure 1. Shapes of Spleens in Percentages

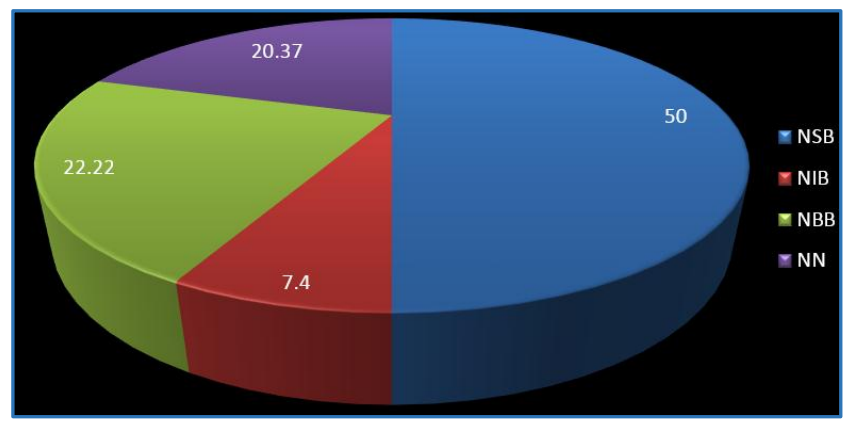

Figure 2. Number of Spleens in Percentages Showing Notches on Borders

NSB- Notch/notches on superior border, NIBnotch/notches on inferior border, NBB- notch/notches on both borders \& NN- no notch.

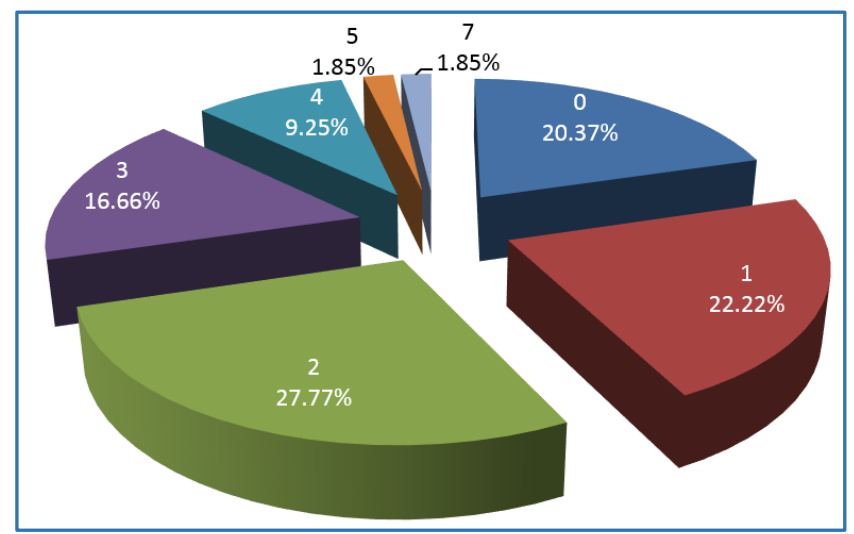

Figure 3. Number of Spleens in Percentages Showing Number of Notches on Borders
No notch- $20.37 \%, 1$ notch- $22.22 \%, 2$ notches- $27.77 \%, 3$ notches- $16.66 \%, 4$ notches- $9.25 \%, 5$ notches- $1.85 \%, 7$ notches- $1.85 \%$

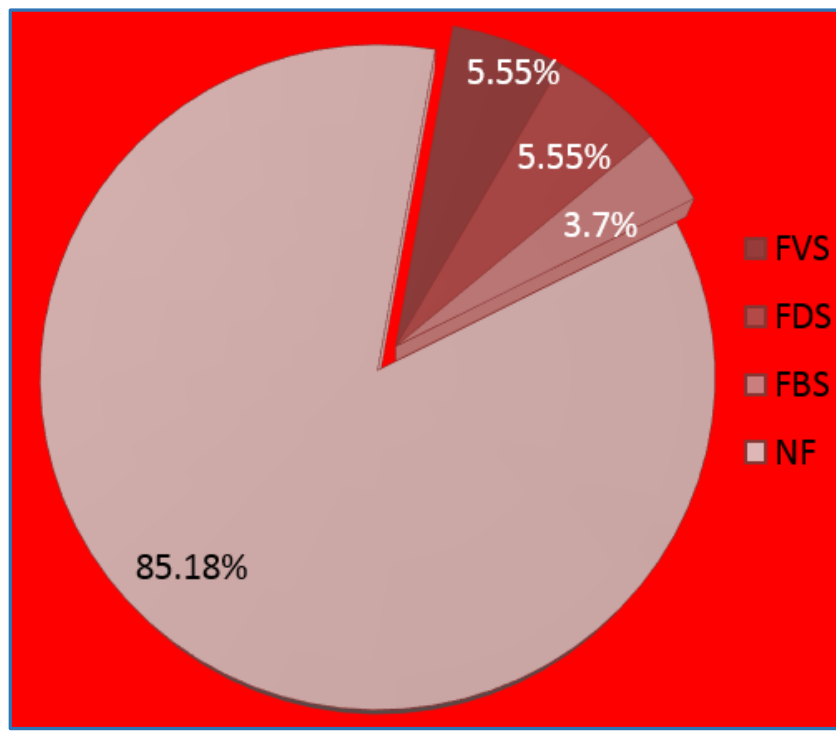

Figure 4. Number of Spleens in Percentages Showing Fissures

FVS [Fissures on visceral surface]- 5.55\%, FDS- [Fissures on diaphragmatic surface]- 5.55\%, FBS [Fissures on both surfaces]- 3.7\% \& NF [No fissures]- $85.18 \%$

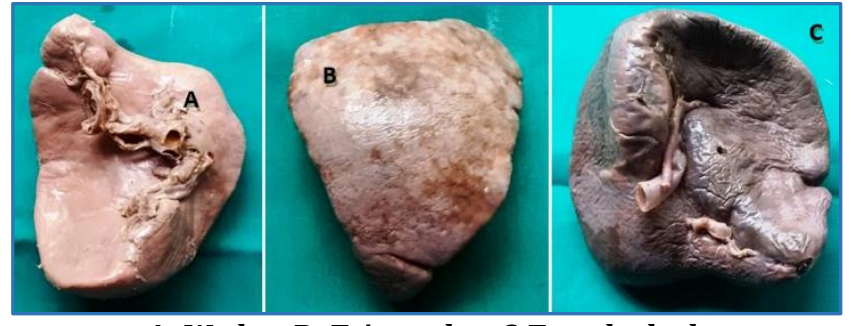

A- Wedge, B- Triangular, C-Tetrahedral

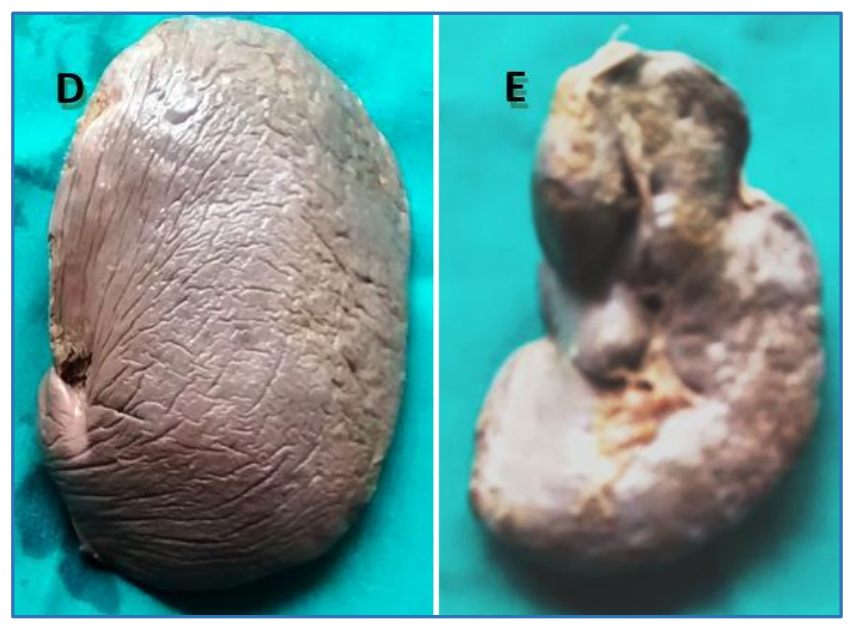

D- Oval, E- Irregular

Figure 5. Different Shapes of Spleen 


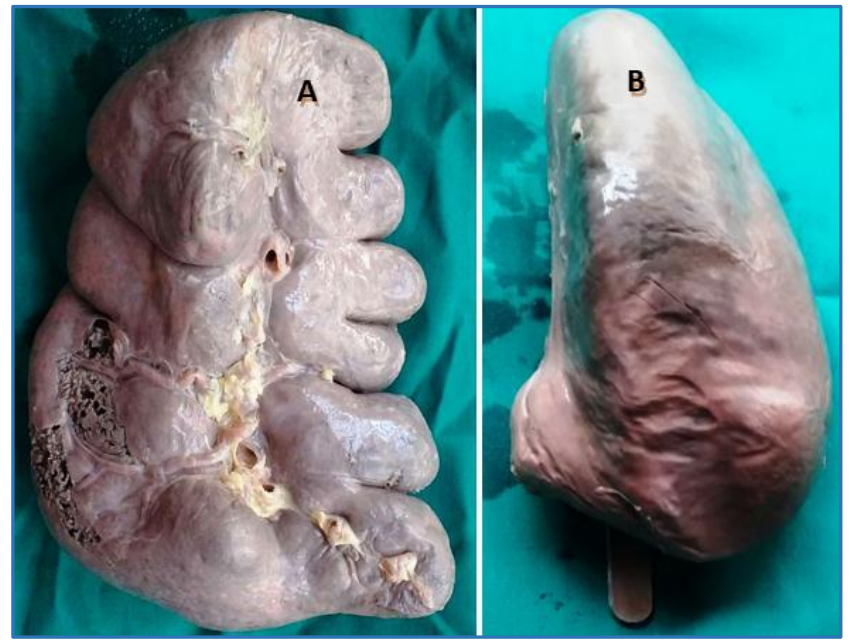

Figure 6. Notches on Borders of Spleen, A- Notches on both Borders, B- No Notch
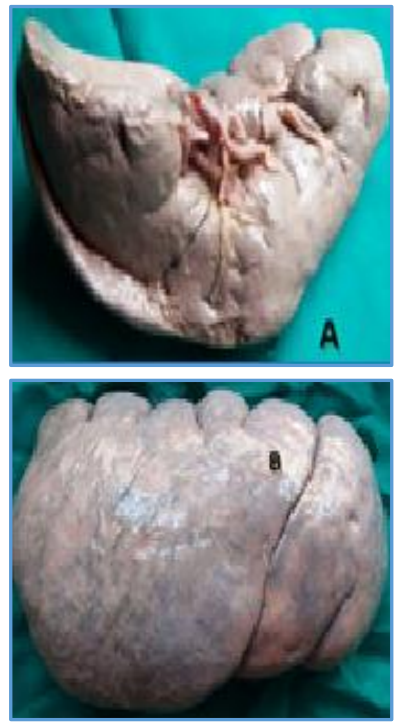

Figure 7. Fissures on Surfaces of Spleen, A- Fissure on Visceral Surface, B- Fissures on Diaphragmatic Surface

\begin{tabular}{|c|c|c|c|c|c|c|}
\hline Shapes & Hollinshed 6 & P. Chavare ${ }^{7}$ & Sivanageswara ${ }^{8}$ & Chaudhari ${ }^{9}$ & Sangeeta10 & Present Study \\
\hline Wedge & $44 \%$ & $61.26 \%$ & $40 \%$ & $33.87 \%$ & $34 \%$ & $38.88 \%$ \\
\hline Triangular & $42 \%$ & $12.61 \%$ & $32 \%$ & $19.35 \%$ & $34 \%$ & $22.22 \%$ \\
\hline Oval & ---- & $3.60 \%$ & $8 \%$ & $8.06 \%$ & $9.4 \%$ & $20.37 \%$ \\
\hline Tetrahedral & $14 \%$ & $21.62 \%$ & $20 \%$ & $32.25 \%$ & $15 \%$ & $11.11 \%$ \\
\hline Irregular & $-\cdots-$ & $0.90 \%$ & ---- & ---- & ---- & $7.40 \%$ \\
\hline \multicolumn{7}{|c|}{ Table 1} \\
\hline
\end{tabular}

\begin{tabular}{|c|c|c|c|c|}
\hline Study by & NSB & NIB & NBB & NN \\
\hline Das $^{11}$ & $98 \%$ & $2 \%$ & ---- & \\
\hline Nayak $^{12}$ & $50 \%$ & ---- & ---- & $50 \%$ \\
\hline${\text { P. } \text { Chavare }^{7}}^{2}$ & $74.76 \%$ & $24.32 \%$ & ---- & \\
\hline Sivanageshwara $^{8}$ & $64 \%$ & $20 \%$ & ---- & $16 \%$ \\
\hline Chaudhari $^{9}$ & $50 \%$ & $24.19 \%$ & $9.67 \%$ & \\
\hline $\begin{array}{c}\text { Siva } \\
\text { Chidambaram }\end{array}{ }^{10}$ & $63.33 \%$ & $10 \%$ & $10 \%$ & $16.67 \%$ \\
\hline Present study & $50 \%$ & $7.40 \%$ & $22.22 \%$ & $20.37 \%$ \\
\hline \multicolumn{5}{|c|}{ Table 2 } \\
\hline
\end{tabular}

\section{DISCUSSION}

Spleen being a haziest entity, its morphological study is a need of present era. It is a variable organ with respect to its size, shape, weight, notches \& fissures. It is very difficult to analyse whether the spleen is normal or abnormal on the basis of its shape so this is a humble trial of the study to find out percentage of various shapes of spleen.

Many researchers studied morphology of spleens. Das et al $^{11}$ studied 100 spleens, Nayak et al $^{12}$ \& Sivanageswara Rao et $\mathrm{al}^{8}$ studied 50 spleens each, Prashant Chaware et $\mathrm{al}^{7}$ studied 111 spleens, Chaudhari et al ${ }^{9}$ studied 62 spleens, Sangeeta et al ${ }^{13}$ studied 53 spleens \& Siva Chidambaram et $\mathrm{al}^{10}$ studied 60 spleens. Their findings were correlated with the present study.

Besides these, Chaudhari et $\mathrm{al}^{9}$ \& Sangeeta et al ${ }^{13}$ observed heart-shaped spleens in $6.45 \%$ \& $3.7 \%$ respectively, while Sangeeta et al $^{13}$ observed semilunar spleens in $3.7 \%$.

Few investigators studied about number of notches and fissures. Das et al ${ }^{11} \&$ Nayak et al ${ }^{12}$ found anomalous splenic fissure in $1 \%$, while Siva Chidambaram ${ }^{10}$ noted anomalous splenic fissure in $6.6 \%$. In the present study, extensive

observation about occurrence of splenic fissures on the surfaces as well as its percentages were calculated. Absence of notch can be confused with other viscera. The fissures can be differentiated from laceration of spleen by its smooth contour \& sharp edge. The various shapes and notches of spleen observed by various investigators were compared in Table 1 and 2.

Some variations of the spleen may result in diagnostic pitfalls. During clinical examinations for identification of spleen, notches are not the reliable guide. However, in splenomegaly which is commonly seen in cases of malaria, typhoid, leukaemia \& infectious mononucleosis, the anterior end, inferior border \& diaphragmatic surface may become clearly palpable below left costal margin. The notches if present are often exaggerated and may become palpable.

The spleen develops from the coelomic epithelium of the cranial part of the dorsal mesogastrium (Sadler ${ }^{2}$; Standring ${ }^{1}$ ) in the sixth week of intrauterine life. In the early stages, eventual fusion of splenic nodules results into formation of the spleen. The reason behind the presence of notch/notches on the borders is due to improper fusion of the splenic nodules along the borders during development.

It is the need of the present era to have accurate knowledge of morphology of spleen as it reveals ample of variations in its shape, size, about notches \& fissures. The knowledge of morphological variations of spleen is of paramount importance for clinicians during routine clinical examination of abdomen, for surgeons for spleen-related surgeries such as laparoscopic splenectomies, for radiologists for correct radiological diagnosis \& lastly for anatomists for routine dissection. 


\section{CONCLUSION}

Not only the fundamental knowledge of spleen is enhanced by such studies, but it is also of immense help in clinical utility.

\section{REFERENCES}

[1] Standring S. Gray's anatomy: the anatomical basis of the clinical practice. 39th edn. Edinburg: Elsevier Churchill Livingstone, 2005:1239-44.

[2] Sadler TW. Langman's medical embryology. Baltimore, Lippincott Williams \& Wilkins, 2000:277.

[3] Yildiz AE, Ariyurek MO, Karcaaltincaba M. Splenic anomalies of shape, size, and location: pictorial essay. Hindawi Publishing Corporation. The Scientific World Journal 2013;Article ID 321810:1-9.

[4] King H, Shumacker HB. Splenic studies. I. Susceptibility to infections after splenectomy is performed in infancy. Ann Surg 1952;136(2):239-42.

[5] Radhakrishnan S, Iddalgave S, Chandrashekaran K. Multi notched and lobulated spleen: a case report. Journal of Pharmacological and Toxicological Investigations 2015;1(2):45-6.
[6] Hollinshed WH. Anatomy for surgeons. $3^{\text {rd }}$ edn. Vol. 2. New York: Harper and Row 1982:436-45.

[7] Charware PN, Belsare SM, Kulkarni YR, et al. The morphological variations of the human spleen. Journal of Clinical and Diagnostic Research 2012;6(2):159-62.

[8] Setty SRS, Katikireddi RS. Morphometric study of human spleen. Int J Biol Med Res 2013;4(3):3464-8.

[9] Chaudhari M, Maheria $P$, Lakhani $C$, et al. Morphological variations of human spleen and its clinical significance. Int J Med Res Rev 2014;2(1):16-9.

[10] Chidambaram RS, Sridhar S. Morphological variations of spleen: a cadaveric study. Journal of Evidence Based Medicine and Healthcare 2015;2(29):4248-54.

[11] Das S, Abd Latiff A, Suhaimi FH, et al. Anomalous splenic notches: a cadaveric study with clinical implications. Bratisl Lek Listy 2008;109(11):513-6.

[12] Nayak SB, Kumar V, Kumar N, et al. Unusual fissure on the diaphragmatic surface of the spleen-a case report. Int J Anat Var (IJAV) 2012;5:96-8.

[13] Sangeeta M, Varalakshmi KL, Sahana BN. Cadaveric study of morphometry of spleen. Journal of Medical Sciences and Health 2015;1(3):14-7. 